\title{
Self Efficacy Nenek dalam Pemberian ASI eksklusif pada Ibu Menyusui Bayi Usia 1-6 Bulan dengan Pendekatan Health Promotion Model
}

\author{
Heri Wibowo \\ STIKES Pemkab Jombang, Heriwibowo16@gmail.com \\ Ririn Probowati \\ STIKES Pemkab Jombang \\ Abdul Muhith \\ STIKES Pemkab Jombang \\ Monika Savitri \\ STIKES Mojopahit \\ Khamida \\ Universitas Nahdlatul Ulama Surabaya
}

\begin{abstract}
Abstrak
Pentingnya kompetensi nenek dalam pemberian ASI juga sangat berpengaruh terhadap keberhasilan pemberian ASI oleh ibu kepada bayinya. Yukensi (Paguyuban Kakek Nenek ASI) adalah suatu perkumpulan atau paguyuban yang memiliki anggota terdiri dari Kakek dan Nenek yang bertugas dalam kelompok pendukung ASI. Desain penelitian cross sectional. Variabel penelitian: self efficacy nenek, usia cucu, jumlah anak, jumlah cucu dan usia cucu. Sampel nenek aktif datang di POSYANDU lansia desa Ngelele kecamatan Sumobito kabupaten Jombang 2018 sejumlah 68 responden menggunakan simple random sampling dan dianalisis dengan uji Chi-square dengan $\alpha=0.05$. Pengumpulan data bulan September-oktober 2018. Hasil penelitian hampir setengahnya (47\%) mempunyai self efficacy cukup, sebagian pada usia 40-65 tahun. Sebagian besar (87.5\%) self efficacy cukup dengan jumlah anak >2-4 anak. Sebagian besar (78.1\%) self efficacy cukup dengan jumlah cucu 2-4 anak. Sebagian besar (78.1\%) self efficacy cukup dengan usia cucu > 6 bulan. Semua variabel berpengaruh kuat terhadap self efficacy pada variabel jumlah anak dan usia cucu.Variabel yang lain mempunyai hubungan yang lemah. Variabel jumlah anak dan usia cucu yang tinggal dalam serumah. Self efficacy dipengaruhi pengalaman pribadi yang telah dilalui secara nyata berupa keberhasilan dan kegagalan. Seorang nenek yang mempunyai pengalaman saat merawat anaknya dapat memberikan ASI eksklusif akan meningkatkan self efficacy dalam memberikan pendampingan kepada anaknya (ibu yang sedang menyusui) agar anaknya memberikan ASI eksklusif dengan jumlah anak lebih dari satu dan usia cucu lebih dari 6 bulan akan membuat seorang nenek mempunyai self efficacy yang baik. Selain pengalaman self efficacy dapat ditingkatkan melalui Verbal persuasion yang dapat dilakukan berulang.
\end{abstract}

Kata kunci : self efficacy nenek, ASI eksklusif

\begin{abstract}
The importance of grandmother's competence in breastfeeding also greatly influences the success of mother's breastfeeding to her baby. Yukensi (Paguyuban Kakek Nenek ASI) is an association or association that has members consisting of Grandparents and Grandmothers who are in charge of ASI support groups. The study design was cross sectional. Research variables: grandmother's self efficacy, grandchild age, number of children, number of grandchildren and grandchildren age. Active grandmother sample came at POSYANDU elderly Ngelele village, Sumobito sub-district, Jombang regency 2018 number 68 using simple random sampling and analyzed by Chi-square test with $\alpha=0.05$. Data collection from September to October 2018. The results of the study almost half (47\%) had sufficient self efficacy, some at the age of 40-65 years. Most (87.5\%) self efficacy is enough with the
\end{abstract}


number of children $>2-4$ children. Most (78.1\%) self efficacy is enough with the number of grandchildren 2-4 children. Most (78.1\%) self efficacy is enough with grandchildren> 6 months. All variables have a strong influence on self-efficacy on the variable number of children and grandchildren. Other variables have a weak relationship. Variable number of children and the age of grandchildren who live in the house. Self efficacy is influenced by personal experiences that have been traversed in the form of success and failure. A grandmother who has experience in caring for her child can provide exclusive breastfeeding will increase her self efficacy in providing assistance to her child (mothers who are breastfeeding) so that their children provide exclusive breastfeeding with more than one child and grandchildren more than 6 months will make a grandmother have self good efficacy. Besides self-efficacy experience can be improved through Verbal persuasion that can be done repeatedly.

Keywords: grandmother's self-efficacy, exclusive breastfeeding

\section{PENDAHULUAN}

Keluarga adalah unit terkecil dari suatu masyarakat yang terdiri dari dua atau lebih individu yang diikat dalam hubungan darah, perkawinan, atau adopsi yang hidup bersama, berinteraksi satu sama lain, dan memiliki peran sosial masing-masing yang mempunyai tujuan menciptakan dan mempertahankan budaya serta meningkatkan perkembangan fisik, psikologis, dan sosial anggota keluarga yang lain (Efendi, et all., 2009). Anggota keluarga sangat besar pengaruhnya pada anggota keluarga yang lain. Salah satunya adalah nenek.

Hasil studi Agunbiade (2012) di Nigeria Barat menyatakan bahwa nenek atau ibu mertua merupakan seseorang yang berperan dalam produksi kesehatan anak yaitu budaya menyusui. WHO dan UNICEF bekerjasama dalam Global Nutrition Targets 2025 untuk meningkatkan angka cakupan pemberian ASI Eksklusif pada 6 bulan pertama kehidupan sekurang-kurangnya 50\%, hal ini dikarenakan secara global angka cakupan ASI Eksklusif hanya sebesar 38\%. Jadi dalam target ini minimal terjadi $1,2 \%$ kenaikan cakupan ASI setiap tahunnya. Angka ini ditetapkan karena pemberian ASI secara Eksklusif dapat mencegah 800.000 kematian balita atau $13 \%$ dari total kematian balita (WHO, 2014). Di negaranegara Asia seperti negara Thailand cakupan ASI Eksklusifnya sebesar 15\%, China (28\%), Indonesia (42\%), India (46\%), dan Mongolia (66\%). Indonesia termasuk negara yang memiliki cakupan ASI rendah ketiga dibandingkan negara-negara Asia lainnya (UNICEF, 2014).

Cakupan ASI eksklusif memerlukan dukungan ayah, keluarga dan kerabat seperti nenek dan kakek yang merupakan anggota keluarga yang paling dekat dengan ibu. Pentingnya kompetensi nenek dalam pemberian ASI juga sangat berpengaruh terhadap keberhasilan pemberian 
ASI oleh ibu kepada bayinya. Yukensi (Paguyuban Kakek Nenek ASI) adalah suatu perkumpulan atau paguyuban yang memiliki anggota terdiri dari Kakek dan Nenek yang bertugas dalam kelompok pendukung ASI. Kegiatan tersebut dilaksanakan di Posyandu lansia dengan beberapa pembekalan dan pemberian materi oleh tim tenaga kesehatan mengenai pentingnya pemberian ASI Eksklusif selama 6 bulan, dan berlanjut pemberian ASI sampai dengan 2 tahun lamanya.

Orang tua baik mertua atau nenek dianggap lebih mengetahui cara yang lebih baik dalam mengurus anak, karena dianggap telah berpengalaman dan lebih mengerti dalam mengurus anak (Budiasih, 2008). Terkait itu, ada suatu hal yang perlu disayangkan, yakni rendahnya pemahaman ibu, keluarga, dan masyarakat mengenai pentingnya ASI bagi bayi (Prasetyono, 2012). Perkembangan pengetahuan banyak memberikan informasi yang sebagian berbeda dengan pengetahuan yang dianut orang-orang generasi terdahulu. Sehingga, lazim bila terdapat banyaknya perbedaan pendapat antara ibu dengan nenek atau ibu mertua dalam pengasuhan anak (Budiasih, 2008).

Model Promosi Kesehatan adalah suatu cara untuk menggambarkan interaksi manusia dengan lingkungan fisik dan interpersonalnya dalam berbagai dimensi. Health Promotion Model lahir dari penelitian tentang 7 faktor persepsi kognitif dan 5 faktor modifikasi tingkah laku yang memengaruhi dan meramalkan tentang perilaku kesehatan. Model ini menggabungkan dua teori yaitu Teori Pengharapan (Expectancy-Value) dan Teori Pembelajaran Sosial (Sosial Cognitive Theory) dalam perspektif keperawatan manusia dilihat sebagai fungsi yang holistik (Nursalam, 2017).

Promosi Kesehatan dari petugas tenaga kesehatan diharapkan mampu meningkatkan Self Efficacy nenek dalam mengorganisasi dan melaksanakan peran nenek dalam mendorong dan memberikan dukungan akan pentingnya pemberian ASI oleh ibu kepada anaknya dimana bukan hanya skill tetapi juga keputusan yang diambil. Self Efficacy adalah keyakinan individu mengenai kemampuan dirinya dalam melakukan tugas atau tindakan yang diperlukan untuk mencapai hasil tertentu (Bandura, 1997). Self Efficacy diharapkan tiap individu dapat meyakinkan dirinya sendiri terhadap kemampuannya untuk menyelesaikan tugas tertentu. Penelitian Tahap pertama mengidentifikasi faktor; usia, jumlah anak, jumlah cucu dan usia cucu yang mempengaruhi self efficacy nenek. 


\section{METODE}

Desain penelitian cross sectional. Variabel penelitian: self efficacy nenek, usia cucu, jumlah anak yang sudah menikah, nenek aktif datang di POSYANDU lansia desa Ngelele kecamatan Sumobito kabupaten
Jombang 2018 sejumlah 68 orang dengan simple random sampling. Pengambilan data bulan September - Oktober 2018 dan dianalisis menggunakan uji Chi-square dengan $\alpha=0.05$

\section{HASIL PENELITIAN}

Tabel 1. Umur responden, jumlah anak, jumlah cucu yang tinggal dalam satu rumah, usia cucu

\begin{tabular}{|c|c|c|c|c|}
\hline \multirow[t]{2}{*}{ No } & \multirow[t]{2}{*}{ Karakteristik } & \multirow[t]{2}{*}{ Kategori } & \multicolumn{2}{|c|}{ Frekuensi } \\
\hline & & & $\sum$ & $\%$ \\
\hline \multirow[t]{3}{*}{1} & \multirow[t]{3}{*}{ Usia } & $<40$ tahun & 10 & 14.7 \\
\hline & & $40-65$ tahun & 48 & 70.6 \\
\hline & & $>65$ tahun & 10 & 14.7 \\
\hline \multirow[t]{3}{*}{2} & \multirow[t]{3}{*}{ Jumlah anak } & 1 & 6 & 8.8 \\
\hline & & $2-4$ & 52 & 76.5 \\
\hline & & $>4$ & 10 & 14.7 \\
\hline \multirow[t]{3}{*}{3} & \multirow[t]{3}{*}{ Jumlah cucu } & 1 & 26 & 38.2 \\
\hline & & $2-4$ & 38 & 55.9 \\
\hline & & $>4$ & 4 & 5.9 \\
\hline \multirow[t]{2}{*}{4} & \multirow[t]{2}{*}{ Usia cucu } & $<6$ bulan & 13 & 19.1 \\
\hline & & $>6$ bulan & 55 & 80.9 . \\
\hline
\end{tabular}

Dari tabel 1 sebagaian besar (70.6\%) responden berusia 40-65 tahun. Sebagian besar (76.5\%) responden mempunyai anak antara 2-4 orang. Lebih dari setengahnya (55.9\%) responden mempunyai cucu 2-4 anak sebagian besar (88.2\%) mempunyai cucu berusia lebih dari 6 bulan

Tabel 2. Self efficacy responden tentang pemberian ASI eksklusif di POSYANDU LANSIA desa Ngelele Sumobito Jombang 2018

\begin{tabular}{|c|c|c|c|}
\hline No. & Self efficacy & $\mathbf{f}$ & Persentase $(\%)$ \\
\hline 1. & Baik & 16 & 23.5 \\
\hline 2. & Cukup & 32 & 47 \\
\hline 3. & Kurang & 20 & 29.5 \\
\hline \multicolumn{2}{|c|}{ Total } & 68 & 100 \\
\hline
\end{tabular}

Dari tabel 2 hampir setengahnya (47\%) responden mempunyai self efficacy cukup dalam pemberian ASI. 
Heri Wibowo, Ririn Probowati, Abdul Muhith, Monika Savitri, Khamida Self Efficacy Nenek dalam Pemberian ASI Eksklusif pada Ibu Menyusui Bayi Usia 1-6 Bulan dengan

Tabel 3. Tabulasi silang antara Self efficacy dengan usia responden di POSYANDU LANSIA desa Ngelele Sumobito Jombang 2018

\begin{tabular}{|c|c|c|c|c|c|}
\hline \multirow{2}{*}{ No. } & \multirow{2}{*}{ Self Efficacy } & \multicolumn{2}{|c|}{ Usia } & \multicolumn{2}{|c|}{ Jumlah } \\
\hline & & $<40$ & $40-65$ & $>65$ & $\%$ \\
\hline 1. & Baik & $\begin{array}{c}1 \\
(6,3 \%)\end{array}$ & $\begin{array}{c}12 \\
(75 \%)\end{array}$ & $\begin{array}{c}3 \\
(18.7 \%)\end{array}$ & $\begin{array}{c}16 \\
(100 \%)\end{array}$ \\
\hline 2. & Cukup & $\begin{array}{c}3 \\
(9.4 \%)\end{array}$ & $\begin{array}{c}27 \\
(84.4 \%)\end{array}$ & $\begin{array}{c}2 \\
(6,2 \%)\end{array}$ & $\begin{array}{c}32 \\
(100 \%)\end{array}$ \\
\hline 3 & Kurang & $\begin{array}{c}6 \\
(30 \%)\end{array}$ & $\begin{array}{c}9 \\
(45 \%) \\
\end{array}$ & $\begin{array}{c}5 \\
(25 \%)\end{array}$ & $\begin{array}{c}20 \\
(100 \%)\end{array}$ \\
\hline & Jumlah & $\begin{array}{c}10 \\
(14.7)\end{array}$ & $\begin{array}{c}48 \\
(70.6 \%)\end{array}$ & $\begin{array}{c}10 \\
(14,7 \%)\end{array}$ & $\begin{array}{c}68 \\
(100)\end{array}$ \\
\hline
\end{tabular}
tahun.

Dari tabel 3 sebagian besar (84.4\%) self efficacy responden cukup pada usia 40-65

Tabel 4 Tabulasi silang antara Self efficacy responden dengan jumlah anak di POSYANDU LANSIA desa Ngelele Sumobito Jombang 2018

\begin{tabular}{cccccc}
\hline \multirow{2}{*}{ No. } & \multirow{2}{*}{ Self Efficacy } & \multicolumn{2}{c}{ Jumlah anak } & \multicolumn{3}{c}{ Jumlah } \\
\cline { 2 - 5 } & Baik & $0-1$ & $>2-4$ & $>4$ & $\%$ \\
\hline 1. & 2 & 10 & 4 & 16 \\
& & $(12,5 \%)$ & $(62.5 \%)$ & $(25 \%)$ & $(100 \%)$ \\
2. & 1 & 28 & 3 & 32 \\
3. & Cukup & $(3,1 \%)$ & $(87.5 \%)$ & $(9,4 \%)$ & $(100 \%)$ \\
& \multirow{2}{*}{ Kurang } & 3 & 14 & 3 & 20 \\
& & $(15 \%)$ & $(70 \%)$ & $(15 \%)$ & $(100 \%)$ \\
\hline \multirow{2}{*}{ Jumlah } & 6 & 52 & 10 & 68 \\
& & $(8.8 \%)$ & $(76.5 \%)$ & $(14,7 \%)$ & $(100)$ \\
\hline
\end{tabular}

Dari tabel 4 sebagian besar (87.5\%) self efficacy responden cukup dengan jumlah anak >2-4 anak dan hasil analisis uji statistik Chi-kuadrat didapatkan $\rho$-value $=0,009$ dimana nilai $\rho$-value $<\alpha(0,05)$. Maka ada hubungan antara Self efficacy dengan jumlah anak di POSYANDU LANSIA desa Ngelele Sumobito Jombang 2018 dengan hubungan yang sangat kuat.

Tabel 5. Tabulasi silang antara Self efficacy responden dengan jumlah cucu di POSYANDU LANSIA desa Ngelele Sumobito Jombang 2018

\begin{tabular}{lccccc}
\hline \multirow{2}{*}{ No. } & \multirow{2}{*}{ Self Efficacy } & \multicolumn{3}{c}{ Jumlah Cucu } & Jumlah \\
\cline { 2 - 5 } & Baik & $0-1$ & $2-4$ & $>4$ & $\%$ \\
\hline 1. & 3 & 11 & 2 & 16 \\
& & $(18.7 \%)$ & $(68.8 \%)$ & $(12.5 \%)$ & $(100 \%)$ \\
2. & 5 & 25 & 2 & 32 \\
3 & Cukup & $(15.6 \%)$ & $(78.1 \%)$ & $(6,3 \%)$ & $(100 \%)$ \\
& & 18 & 2 & 0 & 20 \\
& Kurang & $(90 \%)$ & $(10 \%)$ & 0 & $(100 \%)$ \\
\hline \multirow{2}{*}{} & \multirow{2}{*}{ Jumlah } & 26 & 38 & 4 & 68 \\
& & $(38.2 \%)$ & $(55.9 \%)$ & $(5.9 \%)$ & $(100)$ \\
\hline
\end{tabular}


6 | Jurnal Ilmiah Kesehatan (Journal of Health Sciences), Vol. 12, No. 2, Agustus 2019, Hal. 1-14

Dari tabel 5 sebagian besar (78.1\%) self efficacy responden cukup dengan jumlah cucu 2-4 anak dan Hasil uji statistik Chi-kuadrat dengan $\rho$-value $=0,005$ dimana nilai $\rho$ value $<\alpha(0,05)$. Artinya ada hubungan antara Seft efficacy dengan jumlah cucu yang tinggal dalam satu rumah di POSYANDU LANSIA desa Ngelele Sumobito Jombang 2018 dengan hubungan yang rendah.

Tabel 6. Tabulasi silang antara Self efficacy dengan usia cucu yang tinggal dalam satu rumah di POSYANDU LANSIA desa Ngelele Sumobito Jombang 2018

\begin{tabular}{lcccc}
\hline \multirow{2}{*}{ No. } & \multirow{2}{*}{ Self Efficacy } & \multicolumn{2}{c}{ Usia } & Jumlah \\
\cline { 3 - 5 } & Baik & $<6$ bulan & $>6$ bulan & $\%$ \\
\hline 1. & 5 & 11 & 16 \\
& & $(31,2 \%)$ & $(68.8 \%)$ & $(100 \%)$ \\
2. & Cukup & 7 & 25 & 32 \\
3 & \multirow{2}{*}{ Kurang } & $(21,9 \%)$ & $(78.1 \%)$ & $(100 \%)$ \\
& & 18 & 2 & 20 \\
& \multirow{2}{*}{ Jumlah } & $(90 \%)$ & $(10 \%)$ & $(100 \%)$ \\
& & 26 & 38 & 68 \\
& & $(38.2 \%)$ & $(55.9 \%)$ & $(100)$ \\
\hline
\end{tabular}

Dari tabel 6 sebagian besar $(78.1 \%)$ self efficacy responden cukup dengan usia cucu $>6$ bulan dan Hasil uji statistik Chi-kuadrat dengan $\rho$-value $=0,07$ dimana nilai $\rho$ value $<\alpha(0,05)$. Artinya ada hubungan antara Seft efficacy dengan usia cucu yang tinggal dalam satu rumah di POSYANDU LANSIA desa Ngelele Sumobito Jombang 2018 dengan hubungan yang kuat.

\section{PEMBAHASAN}

Self effecacy nenek dalam pemberian ASI di POSYADU Lansia.

Dari tabel 2 hampir setengahnya (47\%) responden mempunyai self efficacy cukup dalam pemberian ASI.

Bandura (1997) Self efficacy hasil dari proses kognitif berupa keyakinan, keputusan atau pengharapan tentang seseorang memperkirakan kemampuannya dalam melaksanakan tugas kewajibannya untuk mencapai apa yang menjadi keinginannya. Self efficacy merupakan keyakinan individu terhadap kemampuannya untuk mengatur dan melaksanakan tindakan agar tercapai tujuan yang ditetapkan. Self efficacy juga berusaha untuk menilai keyakinan dan kemampuannya secara individu, agar dapat tercapai apa yang menjadi tujuan.

Self efficacy menekankan pada keyakinan yang dimiliki oleh individu dalam menghadapi situasi yang akan datang yang belum dapat di lihat secara nyata. 
Tidak dapat diprediksi dan penuh dengan ketidakpastian. Self efficacy sangat berpengaruh terhadap tidakan individu tetapi tidak ada faktor lain yaitu: lingkungan, perilaku sebelumnya, variabel personal terutama harapan terhadap hasil yang ikut berperan untuk menghasilkan sebuah perilaku (Bandura, 2011).

Self efficacy secara umum tidak berkaitan dengan kecakapan yang di miliki oleh individu tetapi berkaitan dengan keyakinan mengenai kemampuan individu yang dapat dilakukan dengan kemampuan yang dimilikinya. Self efficacy akan mempengaruhi beberapa aspek dari kognisi dan perilaku individu oleh karena itu perilaku (Bandura, 2011).

Nenek yang mempunyai Self efficacy yang cukup akan merasa kurang mampu melakukan pendampingan kepada anaknya yang sedang menyusui. Self efficacy yang tinggi yang tinggi membuat individu mempunyai kemampuan untuk melakukan pendampingan kepada anaknya dalam memberikan ASI. Seorang nenek yang mempunyai self efficacy yang cukup akan menganggap dirinya tidak mampu memberikan dorongan kepada anaknya untuk memberikan ASI eksklusif kepada bayinya. Nenek akan mudah menyerah pada kondisi yang membuat anaknya tidak memberikan ASI eksklusif apabila anaknya menghadapi masalah dalam pemberian ASI. Seorang anak (ibu yang menpunyai bayi) dalam keadaan sedang menyusui membutuhkan suport sistem (suami, nenek, kakek, kader, saudara dan saudara2) yang kuat untuk dapat memberikan ASI eksklusif.

Seorang ibu yang setelah melahirkan dihadapkan pada konflik yaitu satu sisi kesakitan dan kelelahan setelah melahirkan dan satu sisi menghadapi perubahan peran dengan kehadiran seorang bayi yang membutuhkan perawatan sepenuhnya karena bayi masih bergantung kepada ibunya (Christine Mc Court, 2006). Seorang ibu post partum membutuhkan bantuan ibunya (nenek) untuk memberikan suport dalam mengatasi konflik tersebut agar dapat memberikan ASI eksklusif dan merawat bayinya dengan tenang.

Self efficacy seorang nenek yang mempunyai anak sedang menyusui dapat diperoleh melalui:

\section{Pengalaman keberhasilan (Mastery experience)}

Pengalaman ini didasarkan pada pengalaman-pengalaman pribadi masing yang telah dilalui secara nyata berupa keberhasilan dan kegagalan. Seorang nenek yang mempunyai pengalaman saat merawat anaknya dapat memberikan ASI eksklusif akan meningkatkan self efficacy nya dalam memberikan pendampingan kepada 
8 Jurnal Ilmiah Kesehatan (Journal of Health Sciences), Vol. 12, No. 2, Agustus 2019, Hal. 1-14

anaknya (ibu yang sedang menyusui) agar anaknya memberikan ASI eksklusif. Begitu sebaliknya bila seorang nenek mempunyai pengalaman yang tidak menyenangkan dalam pemberian ASI atau tidak memberikan ASI eksklusif kepada anaknya, nenek akan mempunyai self efficacy yang kurang dalam memberikan pendampingan kepada anaknya dalam pemberian ASI.

Sumber pengalaman yang paling berharga adalah pengalaman diri sendiri. Pengalaman diri sendiri merupakan pengalaman yang selalu membekas dipikiran seseorang. Jika seorang nenek mempunyai pengalaman sendiri dalam memberikan ASI eksklusif dan mempunyai dampak yang baik bagi kesehatan bayi dan dirinya akan meningkatkan self efficacy dalam melakukan pendampingan kepada anaknya untuk memberikan ASI eksklusif. Pengalaman keberhasilan yang berulang kali dilakukan oleh seseorang akan meningkatkan self efficacy. Pengalaman sesorang nenek yang mempunyai anak beberapa dengan pemberian ASI eksklusif dan berdampak baik bagi kesehatan bayi dan diri nenek akan meningkatkan self efficacy dalam melakukan pendampingan kepada anaknya.

Kegiatan keberhasilan dalam memberikan ASI eksklusif seorang nenek akan berdampak yang kuat bagi seorang nenek dan akan menghilangkan dampakdampak negatif seorang nenek saat memberikan ASI eksklusif. Pengalaman dampak negatif dalam memberikan ASI eksklusif yang dialami oleh nenek akan terkurangi dalam memori/ pikiran seorang nenek karena yang diingat-ingat adalah dampak keberhasilan dari pemberian ASI eksklusif. Apabila seorang nenek mempunyai pengalaman yang kurang menyenangkan dalam pemberian ASI eksklusif akan terkurangi dengan usahausaha yang dilakukan nenek untuk memperkuat self efficacy dalam pemberian ASI eksklusif lewat pengalaman diri sendiri bahwa sesulit apapun bisa diatasi dengan usaha terus menerus dan membuahkan hasil yang memuaskan.

2. Pengalaman orang lain (vicorius experience)

Pengamatan akan pengalaman orang lain terhadap keberhasilan dengan masalah yang sama akan menjadikan contoh yang baik bagi seseorang, sebaliknya pengamatan kegagalan orang lain akan menurunkan penilaian seseorang mengenai kemampuan dan individu akan mengurangi usaha seseorang untuk melakukan tindakan. (Bandura, 2011). Pengalaman lewat pengamatan orang lain seolah-olah kita ikut mengalaminya, jika kita melihat orang lain berhasil melaksanakan tugas kita dapat 
menyimpulkan bahwa kita dapat melaksanakan tugas tersebut.

Seorang nenek melihat keberhasilan orang lain dalam memberikan ASI eksklusif akan meningkatkan self efficacynya dalam memberikan pendampingan kepada anaknya dalam memberikan ASI eksklusif.

\section{Persuasi verbal (Verbal persuasion)}

Persuasi verbal merupakan peningkatan self efficacy yang dilakukan melalui saran, nasihat, dan bimbingan melalui verbal agar seseorang dapat meningkatkan kemampuan keyakinan yang dimiliki untuk membantu mencapai tujuan yang ingin dicapai, seseorang yang dinyakinkan melalui verbal akan berusaha lebih keras untuk mencapai suatu keberhasilan (Bandura, 1997).

4. Kondisi fisik dan emosional

Akan mengurangi performace, saat seseorang mengalami ketakutan yang kuat, kecemasan, takut dan tingkat stress yang tinggi kemungkinan akan mempengaruhi self efficacy.

Seorang nenek untuk meningkatkan self efficacy dapat menggunakan persuasi verbal yang dilakukan berulang-ulang agar nenek meyakini kemampuannya dalam memberikan pendampingan pemberian ASI eksklusif. Kegiatan menggunakan persuasi verbal dapat menggunakan sebuah buku/ modul dengan bahasa yang mudah dan gambar-gambar agar mudah untuk memahami cara pemberian ASI eksklusif yang pada akhirnya dapat digunakan untuk melakukan pendampingan dalam pemberian ASI.

Hubungan antara self efficacy nenek dalam pemberian ASI dengan usia responden

Dari tabel 5.3 sebagian besar $(84.4 \%)$ responden berusia lebih dari 40 tahun. Hasil analisis data menggunakan uji statistik Chi-kuadrat didapatkan $\mathrm{p}$ value $=$ 0,008 dimana nilai $\rho$ value $<\alpha(0,05)$. Maka tidak ada hubungan antara Self efficacy dengan usia responden di POSYANDU LANSIA desa Ngelele Sumobito Jombang 2018. Menurut Bandura (1997) self efficacy dipengaruhi oleh Tingkat usia. Semakin bertambah usia akan mempengaruhi self efficacy ibu bekerja.

Self-efficacy terbentuk melalui proses belajar sosial yang dapat berlangsung selama masa kehidupan. Ibu yang lebih tua cenderung memiliki rentang waktu dan pengalaman yang lebih banyak dalam melakukan pengasuhan cara stimulasi pertumbuhan jika dibandingkan dengan ibu yang lebih muda, yang mungkin masih memiliki sedikit pengalamanan dalam cara stimulasi pertumbuahan dan perkembangan dan peristiwa-peristiwa sepanjang dalam hidup seorang ibu akan mempengaruhi self efficacy. Individu yang lebih tua akan lebih 
mampu dalam mengatasi rintangan dalam hidupnya dibandingkan dengan ibu yang lebih muda, hal ini juga berkaitan dengan pengalaman yang ibu miliki sepanjang rentang kehidupannya.

Hubungan antara self efficacy nenek dalam pemberian ASI dengan jumlah anak.

Hasil analisis uji statistik Chi-kuadrat didapatkan $\mathrm{p}$ value $=0,009$ dimana nilai $\rho$ value $<\alpha(0,05)$. Maka ada hubungan antara Self efficacy dengan jumlah anak di POSYANDU LANSIA desa Ngelele Sumobito Jombang 2018 dengan hubungan yang sangat kuat.

Jumlah anak yang dimiliki oleh nenek akan mempengaruhi Self effecacy apabila nenek waktu melaksanakan pengasuhan berupa pemberian ASI kepada anaknya. Jumlah anak yang banyak (lebih dari satu) akan membuat nenek mempunyai banyak pengalaman dalam pemberian ASI. Semakin banyak mempunyai anak semakin banyak pengalaman yang dimiliki oleh nenek yang dapat digunakan sebagai pembelajaran pada anak-anak berikutnya. Pengalaman yang menyenangkan dalam pemberian ASI bagi seorang nenek akan mempunyai pengaruh pada pengasuhan pemberian ASI pada anak berikutnya. Nenek sudah merasakan keberhasilan dalam pemberian ASI pada anak sebelumnya akan menjadikan pendorong keyakinan kemampuan yang baik dalam pemberian ASI pada anak berikutnya. Pengalaman keberhasilan seorang nenek akan digunakan sebagai pendorong kepada anaknya agar dapat memberikan ASI kepada cucunya. Self efficacy nenek dalam pemberian ASI yang baik yang didapatkan dari pengalaman langsung diri sendiri akan membawa keberhasilan bagi nenek dalam mempengaruhi anaknya (Ngalim, 2017). Seseorang individu yang memandang rendah kemampuannya sehingga akan mengalami ketidakpuasan dalam kehidupannya, sehingga dibutuhkan evaluasi untuk menilai keyakinan kemampunnya. Bila seseorang memandang rendah kemampuan dalam memberikan ASI karena pengalaman sebelumnya yang tidak menyenangkan (dapat berupa kegagalan dalam memberikan ASI) akan membuat seorang nenek kurang percaya diri dalam memberikan dorongan kepada anak dalam memberikan ASI.

Pengalaman dalam merawat anak yang banyak akan berpengaruh besar pada self efficacy seorang nenek karena didasarkan pengalaman pribadi secara nyata yang berupa keberhasilan dan kegagalan. Pengalaman keberhasilan seseorang akan menaikan self efficacy dan pengalaman kegagalan akan menurunkan self efficacy seseorang. Self efficacy seseorang akan 
berkembang terus menerus melalui serangkaian keberhasilan dan kegagalankegagalan pada umumnya akan terkurangi dengan keberhasilan yang dapat dicapai.

Hubungan antara self efficacy nenek dalam pemberian ASI dengan jumlah cucu yang di asuh

Dari tabel 5 sebagaian besar $(78.1 \%)$ self efficacy responden cukup dengan usia cucu responden mempunyai anak lebih dari 1(satu). Seseorang yang mempunyai anak lebih dari 1 (satu) akan mempunyai pengalaman dalam dalam memberikan ASI. Pengalaman keberhasilan nenek dalam memberikan ASI kepada anaknya akan membuat nenek mempunyai self efficacy yang baik dalam memberikan dorongan kepada anak yang sedang memberikan ASI untuk cucunya. Pengalaman kegagalan yang dialami oleh nenek dalam memberikan ASI akan membuat nenek mempunyai self eficacy yang kurang baik dalam memberikan memberikan dorongan kepada anaknya sedang memberikan ASI untuk cucunya.

Hasil analisis data menggunakan uji statistik Chi-kuadrat didapatkan p value $=$ 0,008 dimana nilai $\rho$ value $<\alpha(0,05)$. Maka ada hubungan antara Self efficacy dengan usia responden di POSYANDU LANSIA desa Ngelele Sumobito Jombang 2018 dengan hubungan yang rendah.
Sumber pengalaman yang paling berharga adalah pengalaman diri sendiri. Pengalaman diri sendiri merupakan pengalaman yang selalu membekas di pikiran seseorang (Bandura, 1997). Jika seorang nenek mempunyai pengalaman sendiri dalam memberikan ASI eklusif dan mempunyai dampak yang baik bagi kesehatan bayi dan dirinya akan meningkatkan self efficacy dalam melakukan pendampingan kepada anaknya untuk memberikan ASI eksklusif. Pengalaman keberhasilan yang berulang kali dilakukan oleh seseorang akan meningkatkan self efficacy. Pengalaman sesorang nenek yang mempunyai anak beberapa dengan pemberian ASI eksklusif dan berdampak baik bagi kesehatan bayi dan diri nenek akan meningkatkan self efficacy dalam melakukan pendampingan kepada anaknya. Kegiatan keberhasilan dalam memberikan ASI eksklusif seorang nenek akan berdampak yang kuat bagi seorang nenek dan akan menghilangkan dampak dampak negatif seorang nenek saat memberikan ASI eksklusif. Pengalaman Dampak negatif dalam memberikan ASI eksklusif yang dialami oleh nenek akan terkurangi dalam memori/ pikiran seorang nenek karena yang diingat-ingat adalah dampak keberhasilan dari pemberian ASI ekslusif. Apabila seorang nenek 
mempunyai pengalaman yang kurang menyenangkan dalam pemberian ASI eksklusif akan terkurangi dengan usahausaha yang dilakukan nenek untuk memperkuat self efficacy dalam pemberian ASI eksklusif lewat pengalaman diri sendiri bahwa sesulit apapun bisa diatasi dengan usaha terus menerus dan membuahkan hasil yang memuaskan.

Hubungan antara self efficacy nenek dalam pemberian ASI dengan usia responden.

Dari tabel 1 sebagian besar (85.3\%) responden berusia lebih dari 40 tahun. Hasil analisis data menggunakan uji statistik Chi-kuadrat didapatkan p value $=$ 0,8 dimana nilai $\rho$ value $<\alpha(0,05)$. Maka tidak ada hubungan antara Self efficacy dengan usia responden di POSYANDU LANSIA desa Ngelele Sumobito Jombang 2018. Menurut Bandura (1997) self efficacy dipengaruhi oleh Tingkat usia. Semakin bertambah usia akan mempengaruhi self efficacy ibu bekerja.

Self efficacy terbentuk melalui proses belajar sosial yang dapat berlangsung selama masa kehidupan. Ibu yang lebih tua cenderung memiliki rentang waktu dan pengalaman yang lebih banyak dalam melakukan pengasuhan cara stimulasi pertumbuhan jika dibandingkan dengan ibu yang lebih muda, yang mungkin masih memiliki sedikit pengalamanan dalam cara stimulasi pertumbuahan dan perkembangan dan peristiwa-peristiwa sepanjang dalam hidup seorang ibu akan mempengaruhi self efficacy. Individu yang lebih tua akan lebih mampu dalam mengatasi rintangan dalam hidupnya dibandingkan dengan ibu yang lebih muda, hal ini juga berkaitan dengan pengalaman yang ibu miliki sepanjang rentang kehidupannya.

Hubungan antara self efficacy nenek dalam pemberian ASI dengan jumlah anak.

Hasil analisis uji statistik Chi-kuadrat didapatkan $\mathrm{p}$ value $=0,009$ dimana nilai $\rho$ value $<\alpha(0,05)$. Maka ada hubungan antara Self efficacy dengan jumlah anak di POSYANDU LANSIA desa Ngelele Sumobito Jombang 2018 dengan hubungan yang sangat kuat.

Jumlah anak yang dimiliki oleh nenek akan mempengaruhi Self effecacy apabila nenek waktu melaksanakan pengasuhan berupa pemberian ASI kepada anaknya. Jumlah anak yang banyak (lebih dari satu) akan membuat nenek mempunyai banyak pengalaman dalam pemberian ASI. Semakin banyak mempunyai anak semakin banyak pengalaman yang dimiliki oleh nenek yang dapat digunakan sebagai pembelajaran pada anak-anak berikutnya. Pengalaman yang menyenangkan dalam pemberian ASI bagi seorang nenek akan 
Pendekatan Health Promotion Model

mempunyai pengaruh pada pengasuhan pemberian ASI pada anak berikutnya. Nenek sudah merasakan keberhasilan dalam pemberian ASI pada anak sebelumnya akan menjadikan pendorong kenyakian kemampuan yang baik dalam pemberian ASI pada anak berikutnya. Pengalaman keberhasilan seorang nenek akan digunakan sebagai pendorong kepada anakanya agar dapat memberikan ASI kepada cucunya. Self efficacy nenek dalam pemberian ASI yang baik yang didapatkan dari pengalaman langsung diri sendiri akan membawa keberhasilan bagi nenek dalam mempengaruhi anaknya. Ngalim (2017) mengemukakan bahwa seseorang individu yang memandang rendah kemampuannya sehingga akan mengalami ketidakpuasan dalam kehidupannya, sehingga dibutuhkan evaluasi untuk menilai kenyakinan kemampunnya. Bila seseorang memandang rendah kemampuan dalam memberikan ASI karena pengalaman sebelumnya yang tidak menyenangkan (dapat berupa kegagalan dalam memberikan ASI) akan membuat seorang nenek kurang percaya diri dalam memberikan dorongan kepada anak dalam memberikan ASI.

Pengalaman dalam merawat anak yang banyak akan berpengaruh besar pada self efficacy seorang nenek karena di dasarkan pengalaman -pengalaman pribadi secara nyata yang berupa keberhasilan dan kegagalan. Pengalaman keberhasilan seseorang akan menaikkan self efficacy dan pengalaman kegagalan akan menurunkan self efficacy seseorang. Self effeicacy seseorang akan berkembang terus menerus melalui serangkaian keberhasilan dan kegagalan-kegagalan pada umumnya akan terkurangi dengan keberhasilan yang dapat dicapai.

Hubungan antara self efficacy nenek dalam pemberian ASI dengan usia cucu.

Hasil uji statistik Chi-kuadrat $\mathrm{p}$ value $=$ 0,07 dimana nilai $\rho$ value $<\alpha(0,05)$. Artinya ada hubungan antara Self efficacy dengan usia cucu yang tinggal dalam satu rumah di POSYANDU LANSIA desa Ngelele Sumobito Jombang 2018 dengan hubungan yang kuat.

Usia cucu yang diasuh oleh nenek sebagian besar sudah berumur lebih dari 6 bulan. Pada usia cucu lebih dari 6 bulan sudah mendapatkan MP ASI (makanan Pendamping ASI) merupakan makanan yang harus diberikan karena bayi sudah membutuhkan variasi dari berbagai jenis makanan untuk pertumbuhan yang optimal. Pada usia > 6 bulan kandungan ASI sudah tidak mencukupi nilai gizi bagi seorang bayi.

Nenek yang mempunyai cucu lebih dari 6 bulan dalam setiap harinya sudah melalui 
selama 6 bulan dalam mendampingi anak dalam memberikan ASI, setelah 6 bulan bayi akan diberikan MP ASI. Nenek akan memberikan dorongan kepada anaknya dalam memberikan MP ASI kepada cucunya agar cucunya mendapatkan makan bergizi sesuai dengan usianya. Nenek sudah mempunyai pengalaman memberikan dorongan selama 6 bulan dalam pemberian ASI

\section{KESIMPULAN}

1) Sebagain besar self efficacy nenek dalam pemberian ASI pada ibu menyusui cukup

2) Faktor jumlah anak dan usia cucu berpengaruh kuat terhadap self efficacy nenek

3) Self efficacy dapat ditingkatkan melalui: Mastery experience, vicorius experience, Verbal persuasion yang dapat dilakukan berulang - ulang.

\section{SARAN}

1) Memperbesar sampel dengan nenek yang mempunyai cucu kurang dari 6 bulan

2) Modifikasi dengan bermacam-macam cara untuk peningkatan self efficacy kepada nenek yang dapat di lakukan di posyandu lansia

\section{DAFTAR PUSTAKA}

Bandura, A., 1977. Self-efficacy: Toward a unifying theory of behavioral change. Psychological Review, 84, pp.191-215. .

DEPKES, 2007 Stimulasi, Deteksi dan Intervensi Dini Tumbuh kembang Anak di Tingkat Pelayanan kesehatan Dasar

Kuntoro, 2010. Metodologi Sampling dan Besar Sampling Pustaka Melat, Surabaya

Muhith.A, Nasir 2011, Buku Ajar Metodologi Penelitian Kesehatan, Yogjakarta: Nuha Medika

Pedoman Umum Pengelolaan POSYANDU. Departemen Kesehatan 2011

Pender, N.J, Murdaugh. C.L\& Parson, M.A., 2002. Health Promotion in Nursing Practice (6th ed) Upper Saddle River(NJ), Person.

Ririn dkk model pengembangan promosi kesehatan peningkatan self efficacy ayah dalam stimulasi pertumbuhan dan perkembangan balita Proceding INC Fakultas Keperawatan Unair 2017

Soetjiningsih, 2007. Tumbuh kembang anak, Jakarta: EGC.

Syamsu Yusuf 2005. Psikologi Perkembangan Anak dan Remaja, Bandung, PT Remaja Rosdakarya

Wong et al, 2008. Buku Ajar Keperawatan Pediatric, Edisi 4 EGC 